\title{
Simulation of location-specific severe thunderstorm events using high-resolution land data assimilation
}

Article

Accepted Version

Creative Commons: Attribution-Noncommercial-No Derivative Works 4.0

Sisodiya, A., Pattnaik, S., Baisya, H., Bhat, G. S. and Turner, A. G. (2019) Simulation of location-specific severe thunderstorm events using high-resolution land data assimilation. Dynamics of Atmospheres and Oceans, 87. 101098. ISSN 0377-0265 doi:

https://doi.org/10.1016/j.dynatmoce.2019.101098 Available at https://centaur.reading.ac.uk/84112/

It is advisable to refer to the publisher's version if you intend to cite from the work. See Guidance on citing.

To link to this article DOI: http://dx.doi.org/10.1016/j.dynatmoce.2019.101098

Publisher: Elsevier

All outputs in CentAUR are protected by Intellectual Property Rights law, including copyright law. Copyright and IPR is retained by the creators or other copyright holders. Terms and conditions for use of this material are defined in the End User Agreement. 


\section{CentAUR}

Central Archive at the University of Reading

Reading's research outputs online 
1 Simulation of location-specific severe thunderstorm events using high resolution land

2 data assimilation

3 Anshul Sisodiya ${ }^{1}$, S Pattnaik*1, H Baisya ${ }^{1}$, G S Bhat ${ }^{2}$ and A G Turner ${ }^{3,4}$

4

$5{ }^{1}$ School of Earth Ocean and Climate Science, Indian Institute of Technology Bhubaneswar,

6 India

$7 \quad{ }^{2}$ Centre for Atmospheric and Oceanic Sciences, Indian Institute of Science Bengaluru, India

$8 \quad{ }^{3}$ Department of Meteorology, University of Reading, Reading, UK

$9 \quad{ }^{4}$ National Centre for Atmospheric Science, University of Reading, Reading, UK

10

11

12

$*$

14 Corresponding Author:

15 Dr. Sandeep Pattnaik

16 School of Earth Ocean and Climate Sciences

17 IIT Bhubaneswar, Argul, Jatni, Khurda -752 050

18 Email: spt@iitbbs.ac.in 
In this study, the impact of different land initial conditions on the simulation of thunderstorms and monsoon depressions is investigated using the Weather Research and Forecasting (WRF) model. A control run (CNTL) and a simulation with an improved land state (soil moisture and temperature) using the High Resolution Land Data Assimilation System (HRLDAS, experiment name: EHRLDAS) are compared for three different rainfall cases in order to examine the robustness of the assimilation system. The study comprises two thunderstorm cases (one in the pre-monsoon and one during the monsoon) and one monsoon depression case that occurred during the Interaction of Convective Organisation, Atmosphere, Surface and Sea (INCOMPASS) field campaign of the 2016 Indian monsoon. EHRLDAS is shown to yield improvements in the representation of location-specific rainfall, particularly over land. Further, it is found that surface fluxes as well as convective indices are better captured for the premonsoon thunderstorm case in EHRLDAS. By analysing components of the vorticity tendency equation, it is found that the vertical advection term is the major contributor towards the positive vorticity tendency in EHRLDAS compared to CNTL, hence improving localised convection and consequently facilitating rainfall. Significant improvements in the simulation of the pre-monsoon thunderstorm are noted, as seen using Automatic Weather Station (AWS) validation, whereas improvements in the monsoon depression are minimal. Further, it is found that vertical advection (moisture flux convergence) is the major driver modulating the convective circulation in localised thunderstorm (monsoon depression) cases and these dynamics are better represented by EHRLDAS compared to CNTL. These findings underline the importance of accurate and high resolution land-state conditions in model initial conditions for forecasting severe weather systems, particularly the simulation of localised thunderstorms over India. 


\section{Introduction}

50

51

52

The eastern part of India is vulnerable to the landfall of intense tropical storms and thunderstorms, which affect lives, livelihood and property in the region. The state of Odisha, located on the east coast of India is highly susceptible to natural disasters arising from thunderstorms (lighting), intense rainfall events from synoptic-scale monsoon low pressure systems (or monsoon depressions), and cyclones (Das, 2017; Mohapatra \& Mohanty, 2005; Dube \& Rao, 2005). The large number of deaths in recent years (the second highest in the country) has led to Odisha being named the "lightning graveyard" of the country. However, only a limited range of studies has been targeted at this region to address the problem. Furthermore, the genesis of localised convection and associated rainfall have several limitations in Weather Research and Forecasting (WRF) (Alvarez et al., 2018). The analysis shows that the underestimation by the model is probably due to inability of model to generate convection, apparently related to processes of larger scale and limitations on describing mesoscale processes that leads to vertical movements capable of producing extreme rainfall. Apart from many other factors, accurate information of the initial state of land and atmospheric conditions plays a major role in rainfall prediction at the numerical weather prediction (NWP) scale. Numerous studies (Osuri et al., 2017; Pielke et al., 2007; Rajesh et al., 2016) have shown that improvement in short-range prediction of boundary layer development, cloud fields and precipitation may rely on detailed representation of land surface physics and accurate initialization of the land state (i.e. soil moisture, soil temperature, vegetation and land use/land cover). The role of patterns of soil moisture and soil temperature in deep convective development and thermodynamic structure of the atmosphere has also been recognised (Taylor et al., 2012), including specifically for northern India (Barton et al., 2019). Baisya (2017) demonstrated that there is strong influence of land surface conditions on precipitation characteristics of monsoon depressions in term of spatial distribution and intensity of rainfall. 
74 Further, they have demonstrated that initial soil moisture condition and soil moisture availability have strong influence on the rainfall spatial distribution and intensity respectively, over the east coast of India.

One of the key roles of soil moisture is to partition the available surface energy into latent and sensible heat fluxes, among which latent heat flux is directly proportional to evapotranspiration, since it is the sum of transpiration, soil evaporation and canopy evaporation (Lawrence et al. 2007; Yuan et al. 2017). These three components of evapotranspiration are calculated within the land surface scheme, thus stressing the role of land-atmosphere interaction in numerical weather prediction models. Taylor et al., 2012 suggested that semiarid regions have more relation between soil moisture and associated precipitation and this mechanism is modulated by any changes in surface fluxes of moisture and heat (latent and sensible). Past studies have suggested that localised Convective Available Potential Energy (CAPE), high surface temperature and elevated moisture content (upper troposphere) are important ingredients to fuel to the eventual development of deep cumulus convective clouds and rainfall (Murugavel et al., 2014; Price et al., 2010).

Monsoon depressions are synoptic-scale systems which form over the Bay of Bengal and move in a westward/north-westward direction and often make their entrance to central India through Odisha, thereby causing heavy rainfall there. It is found that moisture flux convergence is the main source of moisture for such systems, while local evaporation is of lesser importance (Rajesh et al., 2017; Hunt \& Turner, 2017). Rajesh et al., (2017) have already demonstrated improvements in the prediction of rainfall and other convective parameters for monsoon depressions using high resolution land data assimilation techniques.

The major problem limiting the accurate initiation of a model is the scarcity of high spatial resolution observations of the land surface over the model domain. This scarcity of high resolution land surface observations can be overcome by combining satellite observations with 
high resolution land-surface models. In this context, High Resolution Land Data Assimilation System (HRLDAS) is a land data assimilation system based on the Noah Land Surface Model, and is a modelling interface in conjunction with WRF. Its dynamical framework calculates temporal changes in surface energy fluxes such as sensible, latent, ground heat fluxes, net radiation, soil moisture and temperature, soil water content and surface runoff etc., in offline mode (Rajesh et al., 2016 \& 2017). Various assimilation studies have proved that imposing different soil moisture conditions can modulate the surface temperature forecast (due to localised interactions between the land surface and overlying atmosphere), but among nonlocal factors, the horizontal transport of moisture is the dominant parameter impacting the model's predicted rainfall. Eltahir (1998) demonstrated that wet soil moisture would enhance the moist static energy in elevated boundary layer and would be associated with more rainfall. Previous studies have suggested that co-varying patterns of temperature and rainfall indicate strong coupling of the land and atmosphere and implying the need to improve the initial land state to simulate heavy rainfall events (Koster et al., 2005). In addition, assimilation of high resolution satellite data has also been shown to have a positive influence on the dynamic and thermodynamic features of monsoon depressions along with the spatial distribution of the simulated precipitation over India (Kumar et al., 2014). Despite the positive impacts of various data assimilation methods on the prediction skill of forecast rainfall for short-range forecasts (Bohra et al., 2006; Routray et al., 2008), there is a scarcity of this kind of study examining the impact of land surface assimilation on the prediction skill of NWP models for India, especially for improving the forecast of localised heavy rainfall events.

Thus, this manuscript is targeted at addressing this problem particularly over the state of Odisha (east coast India) with the aim to evaluate the influence of improved land surface assimilation on the prediction skill of localised rainfall and to understand associated feedback mechanisms. The method followed is to test the implementation of the HRLDAS scheme in the Weather 
Research Forecast (WRF) model. This study focuses on the INCOMPASS objective to capture the key surface-atmosphere feedback processes in models, and to evaluate the performance of data assimilation techniques on monsoon rainfall.

The paper is structured as follows: in Section 2, the model and the experiment design is discussed, while Section 3 illustrates the results. All the results discussed in Section 3 belong to an inner model domain at simulated at $3 \mathrm{~km}$ resolution. Finally, conclusions and discussions arising from this study are presented in Section 4.

\section{Model, Experiment Design and Data}

\subsection{The WRF model}

The Advanced Weather Research Forecast (WRF-ARW) model version 3.7.1 developed by the National Center for Atmospheric Research (NCAR) and National Center for Environmental Prediction (NCEP) in collaboration with universities is used in this study. The WRF-ARW model is a limited area, non-hydrostatic primitive equation model with multiple options for various physical parameterization schemes (Skamarock et al., 2008). Two nested domains with grid resolutions of 9 and $3 \mathrm{~km}$ with 35 vertical sigma levels and a model top at $50 \mathrm{hPa}$ are considered for this study. The initial and lateral boundary conditions are provided from the

National Centre for Environment Protection (NCEP)-Final (FNL) operational global analysis $\left(1^{\circ} \times 1^{\circ}\right)$ grid at a 6-hourly interval. The physics components include the Noah Scheme for land surface processes (Tewari et al. 2004), Rapid Radiative Transfer Model for General Circulation Models (RRTMG) longwave and shortwave radiative transfer scheme (Iacono et al. 2008), MM5 similarity theory for calculating surface heat and moisture fluxes, WRF Double Moment 6-class scheme for resolving clouds, and Yonsei University Scheme (YSU) for planetary boundary layer parameterization (Jiménez et al., 2012; Lim and Hong, 2010; Hong et al., 2006). The Kain-Fritsch scheme (Kain, 2003) was used for cumulus convection for the outer domain $(9 \mathrm{~km})$ while the inner domain is explicitly resolved. 


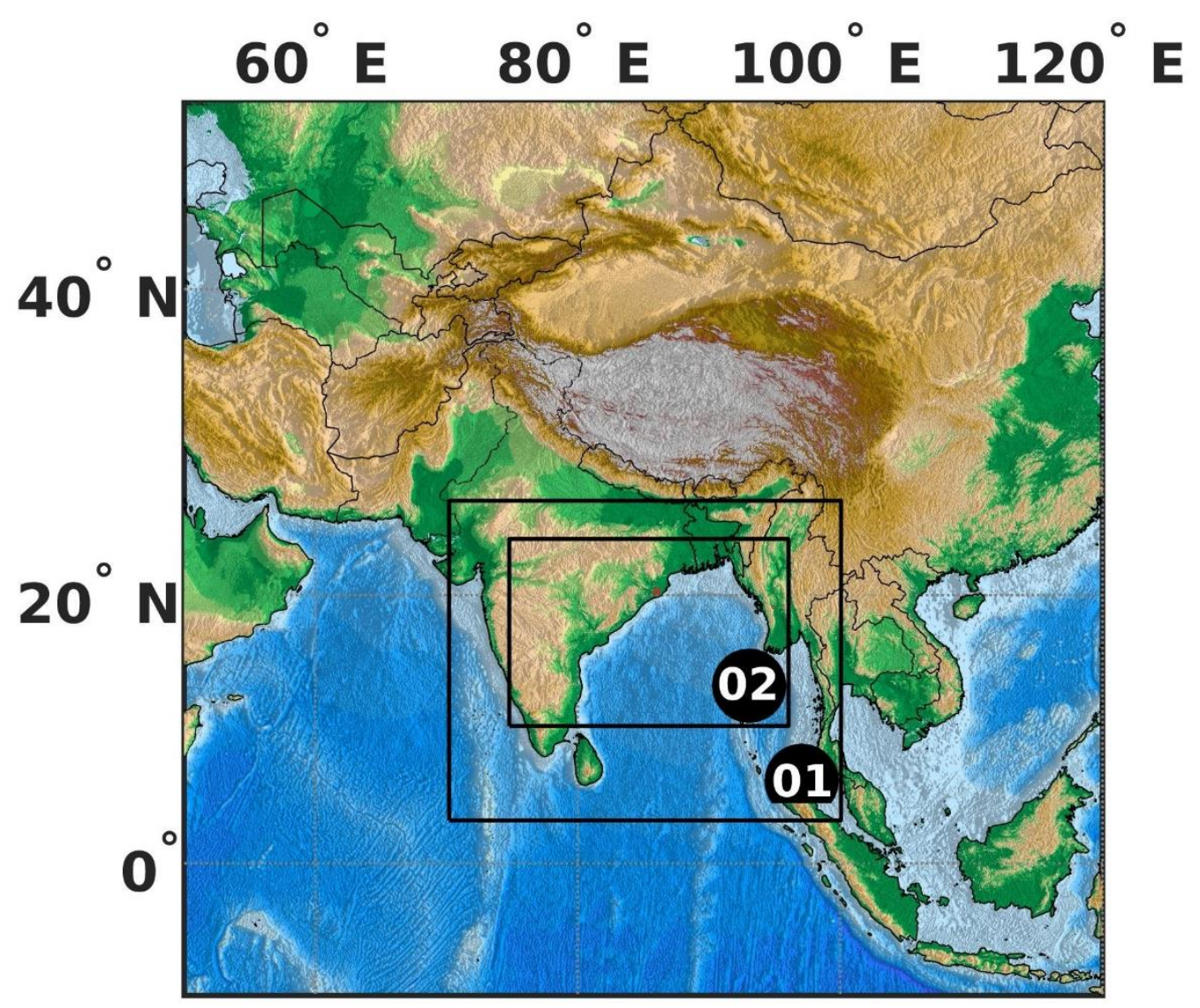

151 Figure 1. The nested outer (01) and inner (02) WRF domains are shown within the wider South Asia region. The red circle on the map shows the location of Argul on the map $\left(85.70^{\circ} \mathrm{E}\right.$, $\left.20.17^{\circ} \mathrm{N}\right)$

\subsection{Experiment design}

HRLDAS is an uncoupled land-surface model which runs offline to evolve the land surface parameters constrained by forcing data from the surface and the above atmosphere (Rajesh et al. 2016 \& 2017; Chen et al., 2007; Nayak et al., 2018). The forcing data used in this experiment is taken from the Global Land Data Assimilation System (GLDAS) at $0.25^{\circ}$ grid and European Centre for Medium Range Weather Forecasting Interim reanalysis data (ERA-Interim) at $0.75^{\circ}$ grid resolution (bilinear interpolated to $0.25^{\circ}$ ). Surface parameters such as precipitation, shortwave and longwave radiation, air temperature, specific humidity and surface pressure are 
taken from Global Land Data Assimilation System (GLDAS) datasets, while $u$ and $v$ components of wind at $10 \mathrm{~m}$ are obtained from ERA-Interim (Dee et al., 2011) to be used as forcing data. The HRLDAS model is first integrated from January 2006 to July 2017 to evolve land surface parameters over the Indian region. The output land state from HRLDAS is assimilated into the WRF model initial conditions. Readers are referred to Rajesh et al. (2016, 2017) for a detailed methodology of HRLDAS.

Both CNTL and EHRLDAS experiments are forced with FNL initial and lateral boundary conditions except that EHRLDAS is additionally being forced by the land state (i.e. soil moisture and soil temperature) obtained from the HRLDAS. In Table 1, we illustrate three different rainfall events occurring over the Argul location associated with different weather systems. Case 1 is a pre-monsoon isolated thunderstorm event, Case 2 is thunderstorm event during the monsoon, while Case 3 is a thunderstorm embedded within a synoptic-scale monsoon depression that occurred in July of 2016. The idea behind considering three rainfall events associated with different weather events is to examine the robustness of HRLDAS in predicting a range of events with heterogeneous origins and different rainfall mechanisms.

Table 1.The three cases taken in this study detailing duration and simulation period of the 178 experiment.

\begin{tabular}{|l|l|l|}
\hline S. No. & Duration (Hours of Prediction) & Experiments \\
\hline Case 1 & 0000 UTC 6 - 0000 UTC 7 March 2017 (24 hr) & i) CNTL \\
\hline Case 2 & 0000 UTC 30 June - 0000 UTC 1 July 2017 (24 hr) & \\
\cline { 1 - 2 } Case 3 & 0000 UTC 26 June - 0000 UTC 29 June 2016 (72 hr) EHRLDAS \\
& & \\
\hline
\end{tabular}




\subsection{Validation data}

For validation, surface parameters including rainfall are obtained from an Automatic Weather

Station (AWS) installed at Argul $\left(85.680^{\circ} \mathrm{E}, 20.170{ }^{\circ} \mathrm{N}\right)$. Further, Global Precipitation

Measurement (GPM) IMERG satellite rainfall data (Huffman, et al., 2014) is used to validate the spatial distribution of rainfall at $0.25^{\circ}$ resolution at half-hourly intervals. In addition, ECMWF Fifth Generation Reanalysis (ERA5) hourly data (Copernicus, 2017) is also used to validate the model-simulated dynamical and thermodynamic parameters.

\section{Results and Discussions}

\subsection{Rainfall}

Figure 2(a-f) shows the Equitable Threat Score (ETS) which measures the fraction of observed and/or forecast events that were correctly predicted for all three cases over land and ocean separately. Except for the lowest rainfall threshold $(0-10 \mathrm{~mm})$, ETS scores are below 0.2 for all simulated cases. Usually in monsoon depression, the rainfall is scattered throughout the domain, but the thunderstorm are isolated and covered a small portion of the domain giving such a low skill score. Among these three cases, EHRLDAS experiments show better rainfall prediction skill. The pre-monsoon thundershower case has the lowest skill compared to the other two monsoonal cases. For Case 1, EHRLDAS improves rainfall prediction over the land as well as ocean particularly for lower rainfall thresholds (i.e. up to $30 \mathrm{~mm}$ ), however, the skill over land is poor for Case 2. In Case 3 (monsoon depression), EHRLDAS shows a higher peak for the lowest rainfall threshold (0-10 $\mathrm{mm})$, but the skill remains poor both over ocean and land for higher rainfall thresholds (Figure $2 \mathrm{e}, \mathrm{f}$ ). This is because the simulations for Case 3 could not capture the pockets of intense rainfall as shown in supplementary Figure S1. We therefore highlight that EHRLDAS has outperformed CNTL in rainfall prediction skill except for Case 

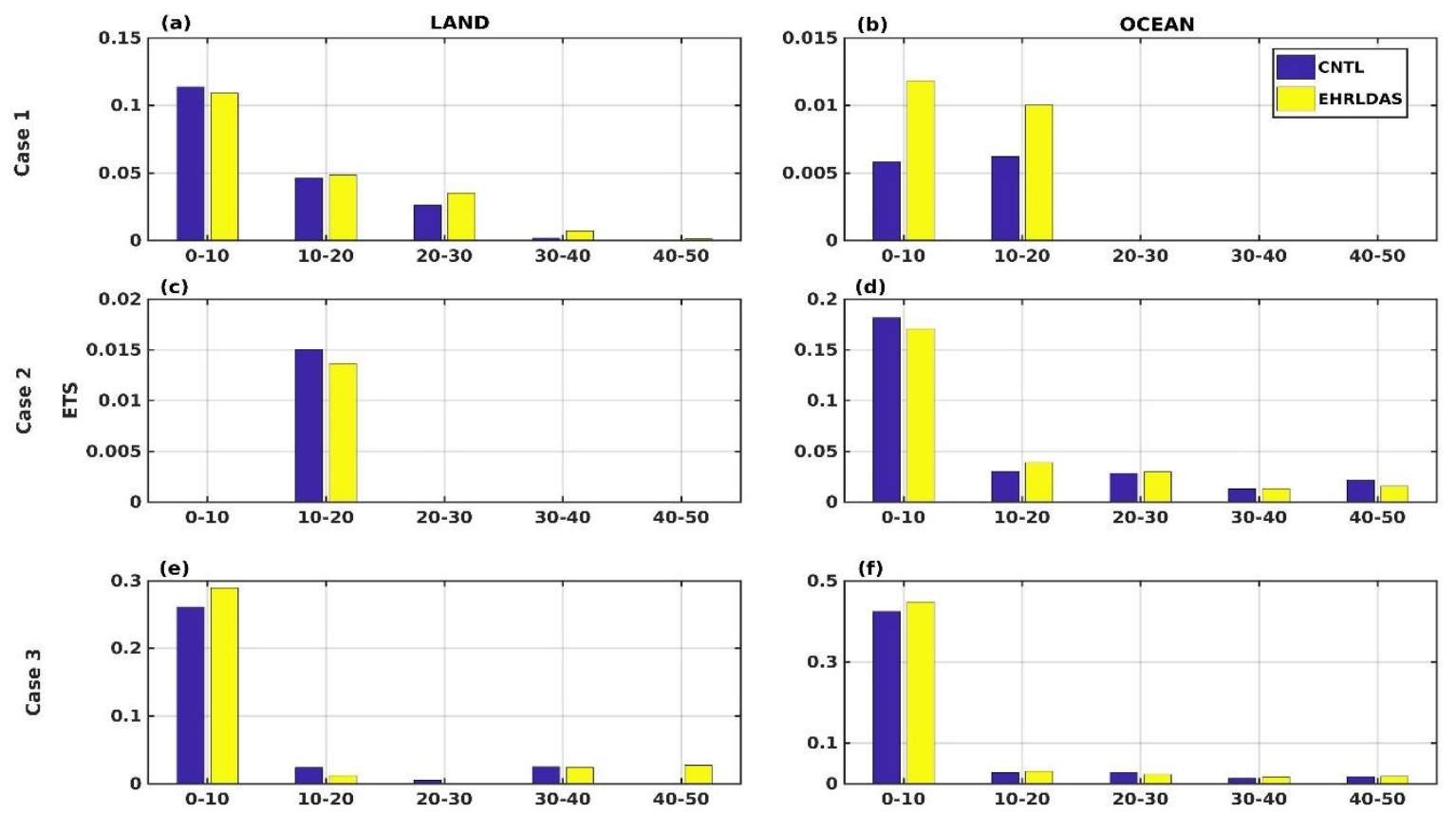

206

207 Figure 2. Equitable Treat Score (ETS) for three cases (a-b) Case 1: 6 March 2017, (c-d) Case 2:

20830 June 2017 and (e-f) Case 3: 28 June 2016 for land (left column) and sea grid points (right

209 column $)$ respectively. Thresholds $0-10 \mathrm{~mm}(0<$ rainfall $<=10), 10-20 \mathrm{~mm}$ includes $(10<$ rainfall

$210<=20)$ and same for other thresholds. ETS is calculated for the $3 \mathrm{~km}$ inner domain and TRMM

211 data is remapped to the model forecast. 

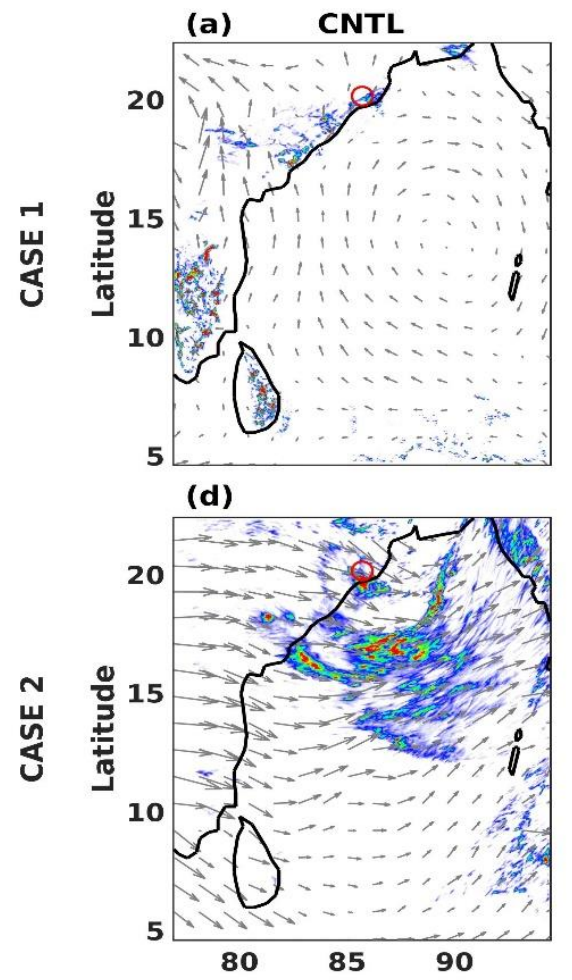

(b) EHRLDAS

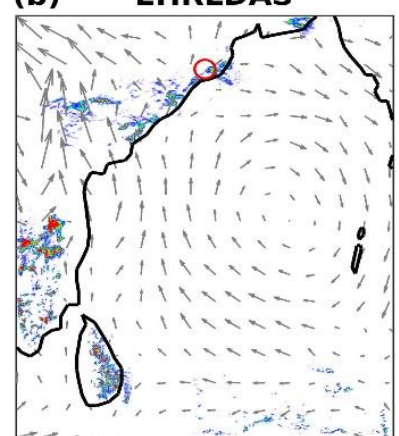

(e)

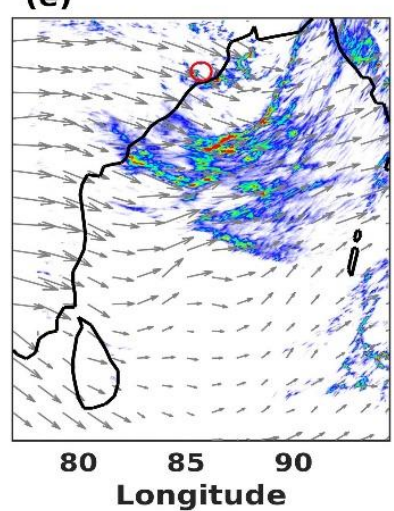

(c) GPM/ERA5

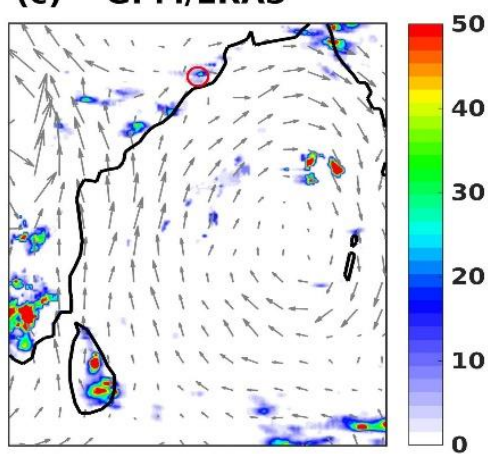

(f)

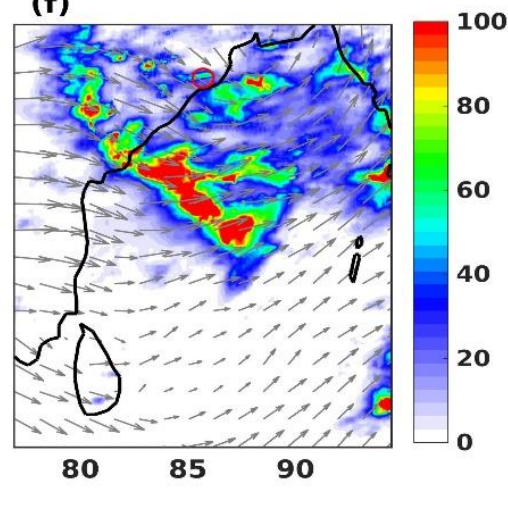

Figure 3(a-f). Day-1 accumulated rainfall $(\mathrm{mm})$ for the first two thunderstorm cases along with wind at $850 \mathrm{hPa}$ i.e. $(\mathrm{a}, \mathrm{b}, \mathrm{c})$ for Case 1 and $(\mathrm{d}, \mathrm{e}, \mathrm{f})$ for Case 2 in model CNTL experiment, EHRLDAS experiment and GPM/ERA5 observations for the inner model domain, respectively. The circle marked in the figure represents the location of Argul.

217 Figure 3 shows the 24-hour accumulated rainfall for Case 1 and Case 2 along with GPMIMERG satellite observations, in each case overlaid with $850 \mathrm{hPa}$ winds from the model or ERA5 as appropriate. An anticyclonic flow is seen over the central Bay of Bengal with strong winds near the east coast of India; these features are well replicated by all experiments. There is not much rainfall for Case 1 over the ocean but isolated pockets of convection and rainfall are noted over the land. Further, intense precipitation pockets seen over the east coast and southern peninsular regions of India have been well reproduced in the EHRLDAS experiment. In addition, it is noted that wind speed at $850 \mathrm{hPa}$, particularly of the southerly winds, has increased in EHRLDAS compared to CNTL (Figure $3 \mathrm{~b}, \mathrm{c}$ ), becoming more realistic. The 
spatial distribution of rainfall for Case 2 is shown in Figure 3(e, f, g, h), where CNTL and

227 EHRLDAS are found to feature similar distributions. But interestingly, EHRLDAS produces a better rainfall distribution over land including over the Argul location (circled). The spatial distribution of rainfall up to Day 3 is shown in Supplementary Figure S1. It is found that the centre of the low is located over the North Bay of Bengal, which propagates north-westward. In general it is clearly evident that EHRLDAS is able to replicate the observed rainfall distribution pattern reasonably well, particularly over the land region even for the isolated premonsoon thunderstorm (Case 1).

Further location-specific validation of model results is carried out at a station observation location i.e. Argul. Figure $4(a, b)$ shows the hourly rain rate from the inner domain for Case 1 and Case 2 (for Case 3 AWS data was not available). The nearest four grid points to the Argul location in model inner domain are used to linearly interpolate model output and then validated against AWS observations. The observed event durations are marked by the dashed red vertical lines in Figure 4. The improvement in the EHRLDAS simulation can be seen in Supplementary Table 2, showing Pearson Correlation Coefficient (PCC) and Root Mean Square Error (RMSE) calculated over the inner domain for the thunderstorm cases (i.e. Case $1 \& 2$ ). It is clearly seen that the EHRLDAS simulations have higher correlation coefficients than CNTL for all surface parameters (rain rate, 2-metre relative humidity, 10 metre wind speed and 2 metre temperature). It is seen that for Case 1, all experiments are able to correctly capture the location as well as timing when compared to observations. The rainfall intensity of the thunderstorm episode was not correctly captured by either experiment, although EHRLDAS is closest to observed values. In Case 2, the EHRLDAS captured the event but with a delay of four hours, whereas CNTL failed to detect the event over the observation location. Figure 3 (c, d) shows the $10 \mathrm{~m}$ wind speed for these two cases. In Case 1, all experiments underestimated the wind speed prior to the event, however the EHRLDAS-simulated time series is closest to observations. 
In general, it is noted that for Case 2, the experiments are not coherent with observations but

252 feature a time lag of approximately four hours, and the wind speed is over-predicted. Further,

253 on examining the temperature and relative humidity (Figure $3 \mathrm{e}-\mathrm{h}$ ), it is noted that EHRLDAS

254 predictions are closest to observed values. In more detail, it is clear that surface air temperature

255 from EHRLDAS closely follows that from observations with a 2-hour time lag. In order to

confirm the better performance of EHRLDAS over CNTL, we have examined its moisture

257

transport and vertical velocity characteristics over the location compared to ERA5

258

(Supplementary Figure S2). We found that there is a better resemblance between ERA5 and

EHRLDAS compared to CNTL. In general the overestimation in CNTL simulation has been reduced in EHRLDAS.

Table 2. Correlation coefficient and Root Mean Square Error for convective Indices (CAPE (J

$\left.\mathrm{kg}^{-1}\right), \mathrm{CIN}\left(\mathrm{J} \mathrm{kg}^{-1}\right)$, KI $\left({ }^{\circ} \mathrm{C}\right)$, TTI $\left.\left({ }^{\circ} \mathrm{C}\right)\right)$ for first two thunderstorm cases with respect to ERA5 data and surface parameters (rain rate $\left(\mathrm{mm} \mathrm{hr}^{-1}\right), 2 \mathrm{~m}$ temperature $\left({ }^{\circ} \mathrm{C}\right), 2 \mathrm{~m}$ relative humidity

$(\%)$ and $10 \mathrm{~m}$ wind speed $\left.\left(\mathrm{m} \mathrm{s}^{-1}\right)\right)$ with respect to AWS station at Argul.

\begin{tabular}{|c|c|c|c|c|c|c|c|c|c|}
\hline \multirow[b]{2}{*}{ PCC } & \multicolumn{5}{|c|}{ Convective Indices(ERA5) } & \multicolumn{4}{|c|}{ Surface parameters (AWS) } \\
\hline & & $\begin{array}{l}\text { CAP } \\
\text { E }\end{array}$ & CIN & KI & TTI & $\begin{array}{l}\text { Rain } \\
\text { Rate }\end{array}$ & $\begin{array}{l}\text { Rel. } \\
\text { Hum. }\end{array}$ & $\begin{array}{l}10 \mathrm{~m} \\
\text { Wind }\end{array}$ & $\begin{array}{l}2 \mathrm{~m} \\
\text { Temp }\end{array}$ \\
\hline \multirow[t]{2}{*}{ Case 1} & CNTL & 0.7 & -0.03 & 0.57 & 0.22 & 0.88 & 0.88 & 0.66 & 0.84 \\
\hline & EHRLDAS & 0.8 & 0.26 & 0.63 & 0.45 & 0.99 & 0.90 & 0.73 & 0.95 \\
\hline \multirow[t]{2}{*}{ Case 2} & CNTL & -0.58 & 0.26 & 0.57 & 0.03 & -0.07 & 0.70 & -0.02 & 0.65 \\
\hline & EHRLDAS & -0.31 & 0.59 & 0.58 & -0.02 & -0.08 & 0.72 & 0.09 & $\mathbf{0 . 7 8}$ \\
\hline RMSE & & $\begin{array}{l}\text { CAP } \\
\text { E }\end{array}$ & $\mathrm{CIN}$ & KI & TTI & $\begin{array}{l}\text { Rain } \\
\text { Rate }\end{array}$ & $\begin{array}{l}\text { Rel. } \\
\text { Hum. }\end{array}$ & $\begin{array}{l}10 \mathrm{~m} \\
\text { wind }\end{array}$ & $\begin{array}{l}2 \mathrm{~m} \\
\text { Temp }\end{array}$ \\
\hline Case 1 & CNTL & 872 & 201.5 & 2.62 & 2.92 & 4.91 & 12 & 3.1 & 2.04 \\
\hline
\end{tabular}




\begin{tabular}{|l|l|l|l|l|l|l|l|l|l|}
\hline & EHRLDAS & $\mathbf{7 0 5}$ & 203.2 & 3.54 & $\mathbf{2 . 5 3}$ & $\mathbf{3 . 5 1}$ & $\mathbf{1 1 . 2 4}$ & $\mathbf{2 . 4 8}$ & $\mathbf{1 . 2 4}$ \\
\hline Case 2 & CNTL & 751 & 66.1 & 0.96 & 6 & 11.94 & 20.42 & 3.41 & 3.15 \\
\cline { 2 - 10 } & EHRLDAS & $\mathbf{6 6 1}$ & $\mathbf{5 3 . 7}$ & 1.33 & $\mathbf{6 . 1 4}$ & $\mathbf{1 1 . 3 4}$ & $\mathbf{1 9 . 4}$ & 3.48 & $\mathbf{2 . 7 7}$ \\
\hline
\end{tabular}

266 From these results, we find clear evidence that between the two thunderstorms (pre-monsoon

267 and mature monsoon cases), the pre-monsoon (Case 1) is well predicted by both models with EHRLDAS performing better across a range of fields than CNTL.
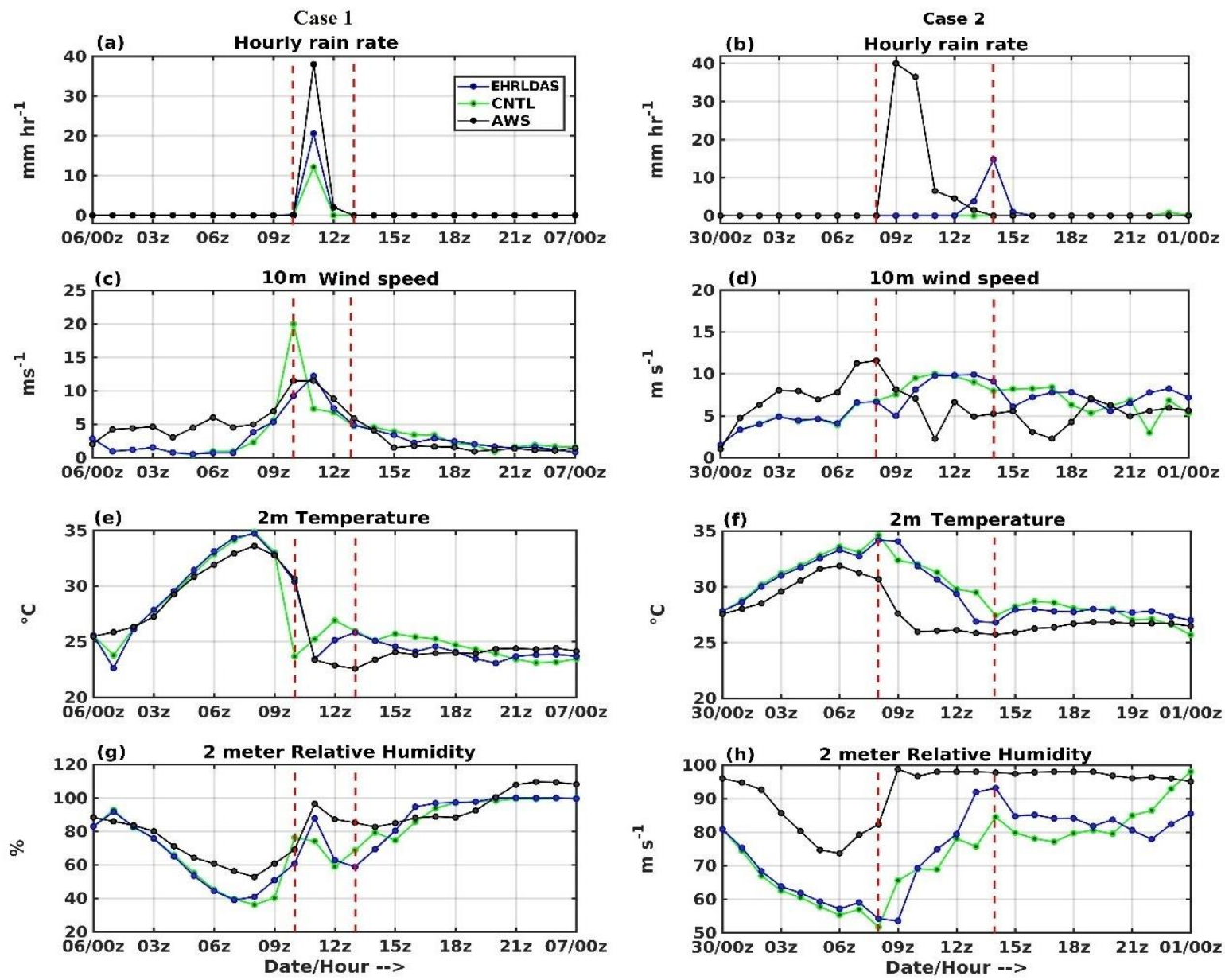

Figure 4. Time series of surface parameters (rain rate $\left(\mathrm{mm} \mathrm{hr}^{-1}\right), 10 \mathrm{~m}$ wind speed $\left(\mathrm{m} \mathrm{s}^{-1}\right), 2$

271 metre temperature $\left({ }^{\circ} \mathrm{C}\right)$ and 2 metre relative humidity $\left.(\%)\right)$ for the two thunderstorm cases i.e.

272 (a, c, e, and g) for Case 1 and (b, d, f, h) for Case 2 from CNTL, EHRLDAS and AWS data.

273 Vertical red lines representing the event duration over $\operatorname{Argul}\left(85.70^{\circ} \mathrm{E}, 20.17^{\circ} \mathrm{N}\right)$. 

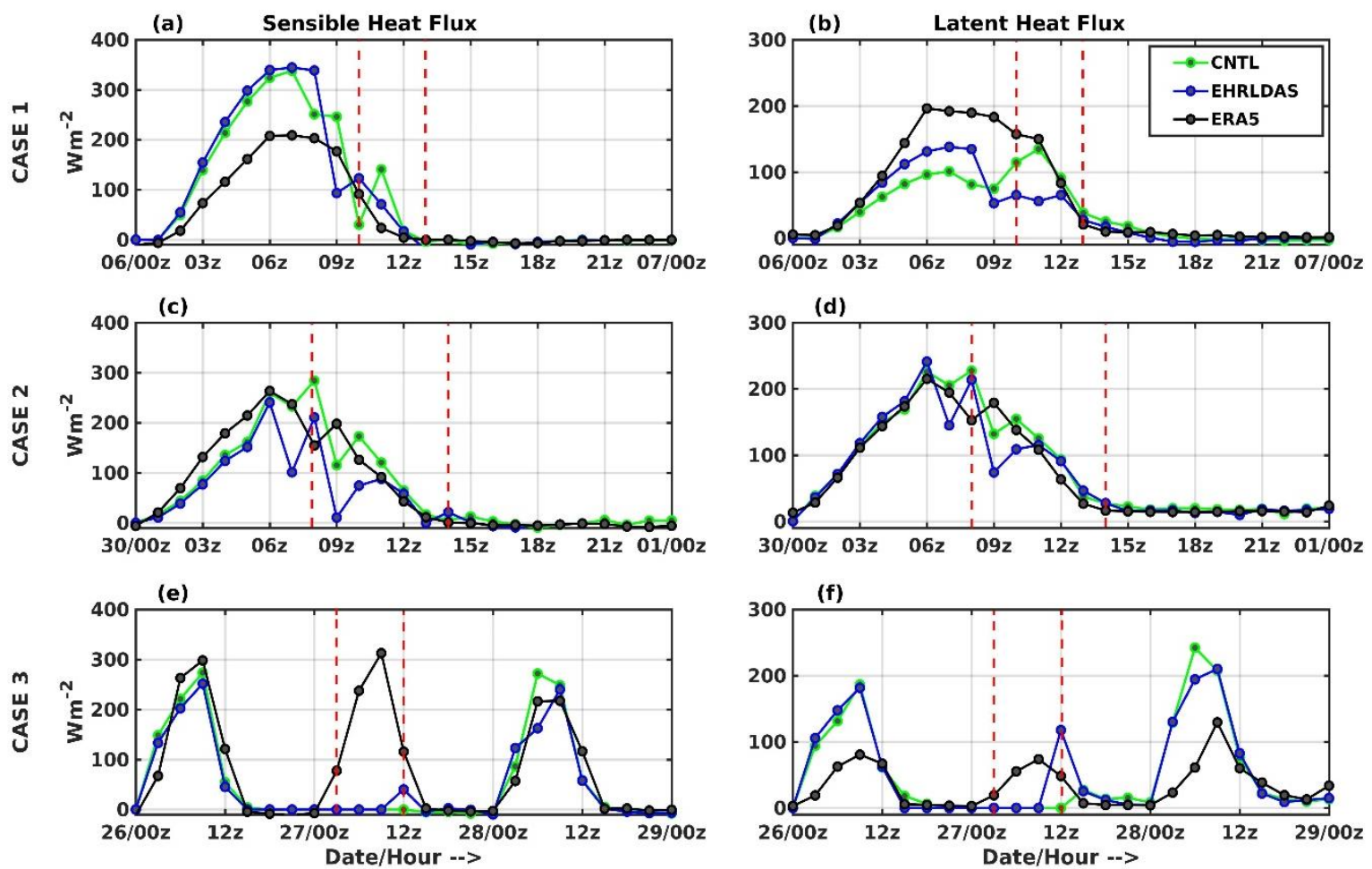

275 Figure 5 Time series of sensible heat flux $\left(\mathrm{W} \mathrm{m}^{-2}\right)$ and latent heat flux $\left(\mathrm{W} \mathrm{m}^{-2}\right)$ over Argul

$276\left(85.70^{\circ} \mathrm{E}, 20.17^{\circ} \mathrm{N}\right)$ for all three cases i.e. $(\mathrm{a}, \mathrm{b})$ for Case $1,(\mathrm{c}, \mathrm{d})$ for Case 2 and $(\mathrm{e}, \mathrm{f})$ for

277 Case3 from CNTL, EHRLDAS (calculated from the nearest four grid points linearly

278 interpolated over Argul location) and AWS data.

\subsection{Surface Fluxes and Thermal Indices}

In order to understand exchanges of heat and moisture between the land and atmosphere and how they may change with the improved surface initialisation, time series of surface latent (LHF) and sensible heat flux (SHF) over the Argul location are shown in Figure 5. Considering the sensitivity of land surface towards different initial conditions, surface fluxes are analysed

284 here and validated against hourly ERA5 surface fluxes (considering reanalysis data as benchmark, and ERA5 data is remapped to the model grids). A sudden decrease in SHF is shown in all experiments two hours prior to the rainfall peak (Figure 5a, b). This reduction may be attributed to an increase of cloud cover leading to reduction of the shortwave radiation and 
surface temperature resulting in reduced SHF. However, the overestimation (underestimation) of SHF (LHF) with respect to ERA5 is seen for both experiments for Case 1. Most interestingly, LHF patterns simulated by EHRLDAS are closer to ERA5, suggesting the impact of improved land state initialisation (soil moisture and temperature) over the location. It is noteworthy to mention that EHRLDAS is able to improve the simulation of this aspect compared to CNTL. Figure $5(\mathrm{e}, \mathrm{f})$ shows the time series of fluxes for the 72-hour simulation period for Case 3 , in which it is interesting to note that the model simulations are able to accurately replicate the surface fluxes for the daytime duration, while EHRLDAS is better at simulating their diurnal changes. However, we note that for 27 June, both the simulations failed to replicate the diurnal changes in SHF, and the LHF is better represented by EHRLDAS compared to CNTL.

Along with the surface fluxes, convective indices associated with thunderstorms are also computed and shown in Figure 6 for the first two cases. The major indices such as Convective Available Potential Energy (CAPE), Convective Inhibition (CIN), Total Totals Index (TTI) thunderstorm for both cases, whereas CNTL failed in this respect (Figure 6a). The enhanced magnitude of CAPE seen in Figure $6 \mathrm{~b}$ is associated with additional LHF into the boundary and K-index (KI) (Williams and Renno', 1993; Miller, 1972; George, 1960) are validated over Argul. The EHRLDAS experiment nicely accumulates CAPE before the occurrence of the layer for Case 2; the magnitude of CAPE is very close to that of ERA5, suggesting the robust impact of EHRLDAS (Figure 5a). Further, two more convective indices i.e. TTI and KI are also plotted for these cases in Figure 6 (e, f, g and h). The higher value of KI indicates the occurrence of intense rainfall, when there is abundant moisture through the mid-levels $(850-$ $500 \mathrm{hPa}$ ), as well as a strong lapse rate. In contrast, TTI takes into account both the static stability and the $850 \mathrm{hPa}$ moisture which is very high in case of monsoon depressions. In general it is clearly evident that EHRLDAS is better able to reproduce the actual instability (in terms of magnitude and pattern in ERA5) compared to CTRL. More precisely, a value above 
the threshold of 30 for KI and 44 for TTI (George, 1960; Miller, 1967) indicates an unstable

314 atmosphere as seen in EHRLDAS (Figure 6e, g). In Case 2, the thermal indices have shown

315 higher values than threshold for the entire simulation (may be due to higher moisture

316 convergence in lower atmosphere during monsoon depression situation and reduced lapse rate)

317 , suggesting the inability of convective indices to indicate any significant changes in synoptic-

318 scale systems.. During the pre-monsoon season, a high value of the KI indicates favourable

319 conditions for thunderstorms, but high values of KI associated with a synoptic low-pressure

320 system or monsoon depression do not mean conditions for thunderstorm as seen in Figure 6(h).

321 The pre-monsoon season is associated with drier troposphere as compared to monsoon

322 depression cases, thus localised effect of convection can bring a variation in KI index but due

323 to high moisture content during monsoon depression it fails to indicate any variation in time

324 series.
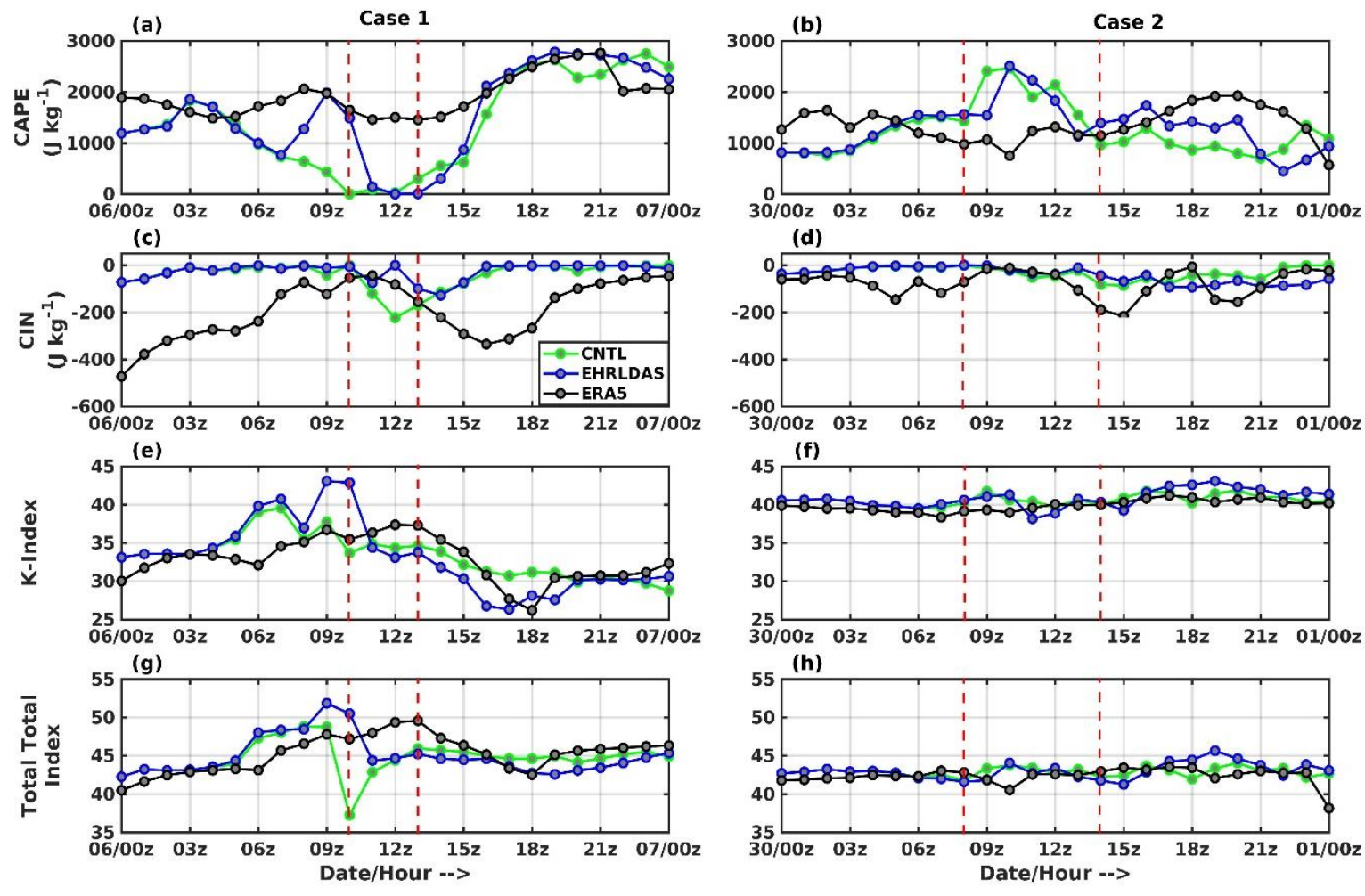
326 Figure 6. Thunderstorm indices (CAPE, CIN, TTI and KI) for the first two cases i.e. Case 1

327 (a, c, e, g) and for Case $2(\mathrm{~b}, \mathrm{~d}, \mathrm{f}, \mathrm{h})$ over the Argul location. (Nearest four grid points are used

328 from inner domain to linearly interpolate over Argul and ERA5 data is remapped to model

329 grid).

$330 \quad 3.3$ Vorticity

331 The convective indices and point-location validation of surface parameters might not 332 comprehensively help in evaluating the impact of EHRLDAS on the monsoon depression

333 (synoptic-scale system). Thus relative vorticity and its components are critically examined over 334 the inner study domain for the $850 \mathrm{hPa}$ pressure level. In this analysis, the vorticity tendency 335 (Dodla and Ratna, 2010) is computed for the whole domain, then the grid points exceeding the $33695^{\text {th }}$ percentile of rainfall (i.e., heavy rainfall) are considered for discussion.

337 Equation (vii) indicates the relative vorticity tendency.

$338 \frac{\Delta \varepsilon}{\Delta t}=-u \frac{\Delta \varepsilon}{\Delta x}-v \frac{\Delta \varepsilon}{\Delta y}-v \frac{\Delta f}{\Delta y}+f \frac{\Delta w}{\Delta z}-w \frac{\Delta \varepsilon}{\Delta z}+\varepsilon \frac{\Delta w}{\Delta z}+\frac{\Delta u}{\Delta z} \frac{\Delta w}{\Delta y}-\frac{\Delta v}{\Delta z} \frac{\Delta w}{\Delta x}$

339

340
A
B
D $\quad \mathbf{E}$
C $\quad$ F
G

341 A: relative vorticity tendency (VORTED)

342

B: horizontal advection (HADV)

343

C: vertical advection (VADV)

344

D: beta term

345 E: stretching term 1

346 F: stretching term 2 (STRETCH)

347

G: tilting term (TILT) 
where, $\varepsilon$ is relative vorticity, $t$ is time step (model output time step, hourly), $f$ is the Coriolis parameter, $\Delta x \& \Delta y$ are the horizontal grid spacing (in metres), $w$ is vertical velocity ( $\left.\mathrm{Pa} \mathrm{s}^{-1}\right)$, $u \& v$ are zonal and meridional components of wind.

The values of the various terms A to $\mathrm{G}$ of the vorticity equation are computed for each hour for the entire period of simulation. Supplementary Figures S3, S4, S5 show the time series of all the components along with rainfall for the three cases. The VORTED term (vorticity tendency) shows an improvement in EHRLDAS compared to CNTL for Case 1 and in general shows a large dependency on vertical advection (VADV). The tilting and stretching terms are found to contribute towards a negative vorticity tendency (anti-cyclonic flow), while horizontal and vertical advection terms are the main contributors to a positive vorticity tendency (consistent with the findings of Yoon and Huang, 2012 for the case 2 and 3. Table 3 shows the correlation of various terms of the vorticity tendency with respect to rainfall. It is seen that the EHRLDAS has increased (bold numbers in the table) the correlation of vertical advection with rainfall for all cases. For Case 2 and Case 3, the improvement in correlation is found for two major terms, i.e. the vertical advection and stretching term, suggesting an enhancement of the relative vorticity in EHRLDAS compared to CNTL. Interestingly, for Case 3, there is no change in correlation values as noted for Case 1 and 2. This suggests the smallest contribution from stretching terms to monsoon depression rainfall that is due to the dominant influence of synoptic scale circulation in the system. Further, for cases 2 and 3, EHRLDAS has reduced the magnitude of overestimated contributions of relative vorticity to rainfall as simulated in CTNL (Supplementary Figure S4 and S5).

Table 3. Correlation of vorticity tendency equation components with precipitation for the grid points with precipitation exceeding the $95^{\text {th }}$ percentile, based on hourly data from 24 hours in Case 1 and Case 2 and 72 hours in Case 3. Number in bold signify the improvement in the EHRLDAS simulation in VADV term. 


\begin{tabular}{|l|l|l|l|l|l|l|l|}
\hline Cases & Experiments & HAD & VADV & TIL & STRETC & VORTED & VORTICIT \\
\hline \multirow{3}{*}{1} & CNTL & 0.13 & 0.43 & -0.53 & -0.34 & 0.48 & 0.01 \\
\cline { 2 - 9 } & EHRLDAS & 0.68 & $\mathbf{0 . 4 4}$ & -0.07 & -0.53 & 0.65 & -0.61 \\
\hline \multirow{3}{*}{2} & CNTL & -0.71 & 0.27 & 0.63 & 0.17 & -0.69 & 0.24 \\
\cline { 2 - 9 } & EHRLDAS & -0.48 & $\mathbf{0 . 5 1}$ & -0.02 & 0.45 & -0.02 & -0.05 \\
\hline \multirow{3}{*}{3} & CNTL & -0.63 & 0.13 & -0.40 & 0.66 & -0.57 & 0.59 \\
\cline { 2 - 9 } & EHRLDAS & -0.23 & $\mathbf{0 . 4 4}$ & -0.61 & 0.66 & -0.02 & 0.09 \\
\hline
\end{tabular}

\section{Conclusions}

This study investigates the impact of two different land states as initial conditions in the WRF model for two thunderstorm cases (one in the pre-monsoon, Case 1 and one mature monsoon case, Case 2) and one monsoon depression system (Case 3) over the |Indian region. For these three cases, different land states are obtained from NCEP Final Operational Global Analysis, FNL (CNTL) and high resolution land data assimilation system (EHRLDAS) at 9 and $3 \mathrm{~km}$ resolutions respectively. The skill of the rainfall prediction is improved in HRLDAS, particularly for the isolated pre-monsoon thunderstorm (Case 1). In general, EHRLDAS results demonstrate an improved prediction of rainfall by capturing high intense rainfall pockets and the associated stronger winds, particularly over the coastal region. These strong winds are closer to the ERA5 re-analysis, suggesting an improved land-ocean thermal contrast in EHRLDAS. In addition, the location-specific representation of thermal indices of convection and surface fluxes are better represented by EHRLDAS in all cases. It is seen that EHRLDAS is able to capture the localised instability conditions (thermal indices) more distinctly over coastal eastern India (i.e. Argul) prior to (up to 2 hours lead time) the occurrence of rain from the pre-monsoon thunderstorm compared to the other two cases (Cases $2 \& 3$ ) which are 
embedded within the large-scale influence of the monsoon circulation. Overall, for the pointlocation validation, EHRLDAS shows more resemblance with ERA5 in terms of fluxes, CAPE and CIN for all cases compared to CNTL. Further, the components of the vorticity tendency equation are computed for those grid points featuring heavy rainfall ( $>95$ th percentile). In general, results suggest that enhancement of vertical advection primarily contributes towards the positive vorticity tendency in these convective systems and particularly for the premonsoon thundershower. Thus EHRLDAS has shown enhanced correlation of the vertical advection term with precipitation for cases 1 and 2 .

We clearly found that better land initialisation is useful for improving the representation of local convective and dynamical processes, which are crucial for better prediction of rainfall particularly over coastal east India. This therefore conveys the need for incorporating an accurate land-surface state in the initial conditions of numerical models to improve rainfall prediction skill, especially at very high resolution $(3 \mathrm{~km})$. Further, we highlight that EHRLDAS shows better representation of convective indices of localised and synoptic-scale severe weather events. Further work would be needed to perform a more comprehensive analysis of pre-monsoon and monsoon storms, for example by systematically comparing day-1 forecasts of all days through spring and summer seasons using this modelling framework.

\section{Acknowledgement}

The authors would like to thank Indian Institute of Technology Bhubaneswar for providing research facilities and helpful assistance required for this purpose. Further, our gratitude to funding agency Indian Institute of Tropical Meteorology (IITM) for providing the financial assistance to carry out this work under Ministry of Earth Science's "INCOMPASS" project (RP-083), Council of Scientific and Industrial Research (CSIR) RP-104, Science and Engineering Board (RP-193). The work of INCOMPASS in the UK was funded by NERC (grant numbers NE/L013886/1 and NE/P003117/1). We are grateful to the National Centre for 
Atmospheric Research (NCAR), ECMWF and National Aeronautical and Space

416

417

Administration (NASA) for models and data sets used to carry out this study.

\section{References}

Mota-Alvarez, A.S., Gàlvez, J., Holguin, A., Estevan, R., Kumar, S., Villalobos, E., MartinezCastro, D., and Silve, Y., 2018. Extreme Rainfall forecast with the WRF_ARW in the Central Andes of Peru, Atmosphere, 9(9), pp.362.

Baisya H., Pattnaik, S., and Rajesh, P.V., 2017. Land surface-precipitation feedback analysis for a landfalling monsoon depression in the Indian region. Journal of Advances in modelling Earth Systems, 9(1), pp.712-726.

Barton, E., Taylor, C. M., Parker, D. J., Turner, A. G., Belušiç, D., Böing, S., Brooke, J. K., Harlow, R. C., Harris, P. R., Hunt, K. M. R., Jayakumar, A. and Mitra, A. K., 2019. An Observational Case Study of Land-Atmosphere Coupling During Monsoon Onset in Northern India. Quarterly Journal of the Royal Meteorological Society, submitted.

Bohra, A.K., Basu, S., Rajagopal, E.N., Iyengar, G.R., Gupta, M.D., Ashrit, R., and Athuiyaman, B., 2006. Heavy rainfall episode over Mumbai on 26 July 2005: Assessment of NWP guidance. Current Science. 90(9), pp1188-1194.

Chen, F., Manning, K.W., Lemone, M.A., Trier, S.B., Alfieri, J.G., Roberts, R., Tewari, M., Niyogi, D., Horst, T.W., Oncley, S.P., Basara, J.B., and Blanken, P.D., 2007. Description and evaluation of the characteristics of the NCAR high-resolution land data assimilation system. Journal of Applied Meteorology and Climatology, 46(6), pp.694-713.

Das, S., 2017. Severe Thunderstorm Observation and Modeling - A Review. Vayumandal, 43(2), pp.1-29.

Dee, D. P., Uppala, S.M., Simmons, A.J., Berrisford, P., Poli, P., Kobayashi, S., Andrae, U., Balmaseda, M.A., Balsamo, G., Bauer, P., Bechtold, P., Beljaars, A.C.M., van de Berg, L., Bidlot, J., Bormann, N., Delson, C., Dragani, R., Fuentes, M., Geer, A.J., Haimberger, 

L., Healy, S.B., Hersbach, H., Hólm, E.V., Isaksen, L., Kållberg, P., Köhler, M., Matricardi, M., Mcnally, A.P., Monge-Sanz, B.M., Morcrette, J.-J., Park, B.K., Peubey, C., de Rosnay, P., Tavolato, C., Thepaut, J.N., and Vitart, F., 2011. The ERA_Interim reanalysis: Configuration and performance of the data assmilation system. Quaterly Journal of Royal Meteorological Society, 137, pp.553-597.

Dube, R.K. and Rao, G.S.P., 2005. Extreme Weather Events over India in the last 100 years. Journal of Indian Geophysical Union, 9(3), pp.173-187.

Dodla, V.B.R, and Ratna, S.B., 2010. Mesoscale characteristics and prediction of an unusual extreme heavy precipitation event over India using a high resolution mesoscale model. Atmospheric Research, 95(3), pp.255-269.

Eitahir, E.A.B., 1998. A soil moisture-rainfall feedback mechanism 1. Theory and observations. Water Resources Research, 34(3), pp.765-776.

George, J.J., 1960. Weather forecasting for aeronautics. Academic press, pp.411.

Hong, S.Y., Noh, Y., and Dudhia, J., 2006. A new vertical diffusion package with an explicit treatment of entrainment processes. Monthly Weather Review. 134, pp.2318-2341.

Huffman G., Bolvin, D.T., and Nelkin, E.J., 2014. Integrated Multi-satellite Retrievals for GPM (IMERG), version 4.4. NASA's Precipitation Processing Center.

Iacono, M.J., Delamere, J.S., Mlawer, E.J., Shephard, M.W., Clough, S.A., and Collins, W.D., 2008. Radiative forcing by long-lived greenhouse gases: Calculations with the AER radiative transfer models. Journal of Geophysical Research Atmospheres, 113(13), pp.29.

Jiménez, P.A., Dudhia, J., Gonzalez-Rouco, J., Navarro, J., Montavez, J.P., and GarciaBustamante, E., 2012. A Revised Scheme for the WRF Surface Layer Formulation. Monthly Weather Review, 140(3), pp.898-918.

Kain, J.S., 2004. The Kain-Fritsch convective parameterization: An update. Journal of Applied 
Meteorology, 43, pp.170-181.

466

467

468

469

470

471

472

473

474

475

476

477

478

479

480

481

482

483

484

485

486

487

488

489

Kumar, P., Kishtawal, C.M., and Pal, P.K., 2014. Impact of satellite rainfall assimilation on Weather Research and Forecasting model predictions over the Indian region. Journal of Geophysical Research: Atmosphere, 119(5), pp.2017-2031.

Koster R.D., Guo, Z., Dirmeyer, P.A., Bonan, G., Chan, E., Cox, P., Davies, H., Gordon, C.T., Kanae, S., Kowalczyk, E., Lawrence, D., Liu, P., Lu, C.-H., Malyshev, S., McAvaney, B., Mitchell, K., Mocko, D., Oki, T., Oleson, K.W., Pitman, A., Sud, Y.C., Taylor, C.M., Verseghy, D., Vasic, R., Xue, Y., and Yamada, T., 2005. GLACE:The Global LandAtmosphere Coupling Experiment. Part 1: Overview. Journal of Hydrometeorology, 7, pp.590-610.

Lawrence, D.M., Thornton, P.E., Oleson, K.W., and Bonan, G.B., 2007. The Partitioning of Evapotranspiration into Transpiration, Soil Evaporation, and Canopy Evaporation in a GCM: Impacts on Land-Atmosphere Interaction. Journal of Hydrometeorology, 8(4), pp.862-880.

Lim, K.S.S. and Hong, S.Y., 2010. Development of an Effective Double-Moment Cloud Microphysics Scheme with Prognostic Cloud Condensation Nuclei (CCN) for Weather and Climate Models. Monthly Weather Review, 138(5), pp.1587-1612.

Miller, R., 1972. Notes on analysis and severe storm forecasting procedures of the Air Force Global Weather Central. Technical Report 200 (Rev.), AWS, U.S. Air Force (Headquarters, AWS, Scott AFB, IL 62225), pp.102.

Mohapatra, M. and Mohanty, U.C., 2005. Some characteristics of very heavy rainfall over Orissa during summer monsoon season. Journal of Earth System Science, 114(1), pp.1736.

Murugavel P., Pawar. S.D., and Gopalakrishnan, V., 2014. Climatology of lightening over Indian region and its relationship with convective available potential energy. International 
journal of Climatology, 34(11), pp1362-1372.

491

492

493

494

495

496

497

498

499

500

501

502

503

504

505

506

507

508

509

510

511

512

513

514

Nayak, H.P., Sinha, P., Satyanarayana, A.N.V., Bhattacharya, A., and Mohanty, U.C., 2018. Performance Evaluation of High-Resolution Land Data Assimilation System (HRLDAS) Over Indian Region. Pure and Applied Geophysics. pp.1-19.

Osuri, K.K., Nadimpalli, R., Mohanty, U.C., Chen, F., Rajeevan, M., and Niyogi, D., 2017. Improved prediction of severe thunderstorms over the Indian Monsoon region using highresolution soil moisture and temperature initialization. Scientific Reports, pp.1-12.

Pielke, R.A., Adegoke, J., BeltrànPrzekurat, C.A., Hiemstra, C.A., Lin, J., Nair, U.S., Niyogi, D., and Nobis, T.E., 2007. An overview of regional land-use and land-cover impacts on rainfall. Tellus, Series B: Chemical and Physical Meteorology, 59(3), pp.587-601.

Price, C., 2000. Evidence for a link between global lightning activity and upper tropospheric water vapor. Nature, 406, pp.290-293.

Rajesh, P.V., Pattnaik, S., Rai, D., Osuri, K.K., Mohanty, U.C., and Tripathy, S., 2016. Role of land state in a high resolution mesoscale model for simulating the Uttarakhand heavy rainfall event over India. Journal of Earth System Science, 125(3), pp.475-498.

Rajesh, P.V., Pattnaik, S., Mohanty, U.C., Rai, D., Baisya, H., and Pandey, P.C., 2017. Land surface sensitivity of Monsoon depressions formed over Bay of Bengal using improved high resolution land state. Dynamics of Atmospheres and Oceans, 80, pp.155-172.

Routray, A., Mohanty, U.C., Niyogi, D., Rizvi, S.R.H., and Osuri, K.K., 2008. Simulation of heavy rainfall events over Indian region using WRF-3DVAR data assimilation system. Meteorology and Atmospheric Physics. 106, pp107-125.

Skamarock, W.C., Klemp, J.B., Dudhia, J., Gill, D.O., Barker, D.M., Wang, W., and Powers, J.G., 2005: A description of the Advanced Research WRF Version 2. NCAR Tech. Note NCAR/TN-468+STR, pp.88.

Taylor C.M., De Jeu, R.A.M., Guichard, F., Harris, P.P., and Dorigo, W.A., 2012. Afternoon 

rain more likely over drier soils. Nature, 489, pp.423-426.

516

517

Tewari, M., Chen, F., Wang, W., Dudhia, J., Lemone, M.A., Mitchell, K., Ek, M., Gayno, G., Wegiel, J., and Cuenca, R., 2004. Implementation and verification of the unified NOAH land surface model in the WRF model. 20th conference on weather analysis and forecasting/16th conference on numerical weather prediction, pp.11-15.

Turner, A. G., Bhat, G. S., Martin, G. M., Parker, D. J., Taylor, C. M., Mitra, A. K., Tripathi, S. N., Milton, S., Rajagopal, E. N., Evans, J., Morrison, R., Pattnaik, S., Sekhar, Bhattacharya, B. K., Madan, R., Mrudula, G., Fletcher, J. K., Willetts, P. D., Menon, Marsham, J. et al., 2019. Interaction of Convective Organisation with Monsoon Precipitation, Atmosphere, Surface and Sea: the 2016 INCOMPASS field campaign in India. Quarterly Journal of the Royal Meteorological Society, submitted.

Wei, J., Su, H., and Yang, Z.-L., 2015. Impact of soil moisture convergence and soil moisture on precipitation: a case study for the southern states with implications for the globe. Climate Dynamics, pp.1-15.

Williams, E. and Renno', N. 1993. An analysis of the conditional instability of the tropical atmosphere. Monthly Weather Review, (121)21, pp.364

Yoon, J. H., and Huang, 2012. W.R., Indian Monsoon Depression: Climatology and Variability. Modern Climatology, 13, pp.45-72.

Yuan, G., Zhang, L., Liang, J., Cao, X., Liu, H., and Yang, Z.,, 2017. Understanding the partitioning of the available energy over the semi-arid areas of the loess Plateau, China. Atmosphere, 8(5).

Zhang H., and Frederiksen C.S., 2002. Local and Nonlocal Impacts of soil moisture initialization on AGCM seasonal forecast: A Model Sensitive Study. Journal of Climate, 16(13), pp.2117-2137.

Zhou, X., and Geerts, B., 2013. The influence of soil moisture on the plenaetary boundary layer 

Weather Review, 141, pp.1061-1078. 